\title{
Design Science Evaluation for Enterprise Architecture Business Value Assessments
}

\author{
Martin Meyer, Markus Helfert \\ Dublin City University, Glasnevin, Dublin 9, Ireland \\ \{mmeyer, markus.helfert\}@ computing.dcu.ie
}

\begin{abstract}
In our research we aim to assess the value contributions of Enterprise Architecture (EA) to an organization that allows a structured and effective way of strategically aligning business with information technology. We have designed and built an Enterprise Business Value Assessment framework within an organizational context following a Design Science Research (DSR) methodology. Our challenge presented in this paper is to evaluate this approach and show how we can effectively determine the relevant criteria and adapt an appropriate evaluation method. Discussing this challenge we propose an evaluation approach using the Measurement and Analysis Infrastructure Diagnostic (MAID) method.
\end{abstract}

Keywords: Design Science Research, Evaluation, Business Value Framework, Enterprise Architecture.

\section{Introduction}

Enterprise Architecture (EA), a discipline that roots back to the 1980 s, is a way to ensure a company's strategic business-information technology (IT) alignment in order to leverage the desired level of business value by establishing an informed governance and strategic management function $[1,2]$. Business strategies are mostly related to business value, i.e. companies are business value driven. The assessment of business value spawned a myriad of approaches and is still an intensely discussed topic in literature and practice. Consequently, EA is crucial for an effective way to analyze and improve business, especially for large organizations. Nevertheless, it is not a trivial task to assess EA in terms of business value.

Therefore, the motivation for our main research endeavor stems from the fact that the EA function in an organizational context is not entirely understood in terms of performance and business value [3-7]. Notably, we measure performance and communicate business value as proposed in [8]. Many EA function fall into the category of intangible assets [9] and are therefore difficult to measure. In our research we aim to develop appropriate metrics to measure these intangible assets [3, 10]. But not only the design of metrics alone is of our concern, we have to align them with appropriate goals according to the current strategy in organizations [11]. In our previous work, we 
developed an Enterprise Architecture Business Value (EABV) assessment approach that is constituted of four IT artifacts.

However, how do we actually evaluate such business value assessment approaches? The research presented in this paper focuses on this challenge, and discusses the evaluation of our approach within a Design Science Research (DSR) context. To answer this question, we reviewed relevant literature as well as business value assessment approaches. Reviewing the literature on evaluation in a DSR context, we identified the need for suitable evaluation methods, especially when considering an organizational context. In addition, we design and evaluate our assessment approach within an organizational context and obtain feedback from subject matter experts in practice.

\section{Design Science Research and Evaluation}

In order to develop the proposed EABV assessment approach, we employ an adapted Design Science Research (DSR) methodology proposed for example in [12]. Our DSR artifact build cycle is based on [13, 14]. Fig. 1 illustrates the main focus of this paper: the evaluation phase of Design Artifacts. Details on our DSR methodology, refer to $[15,16]$.

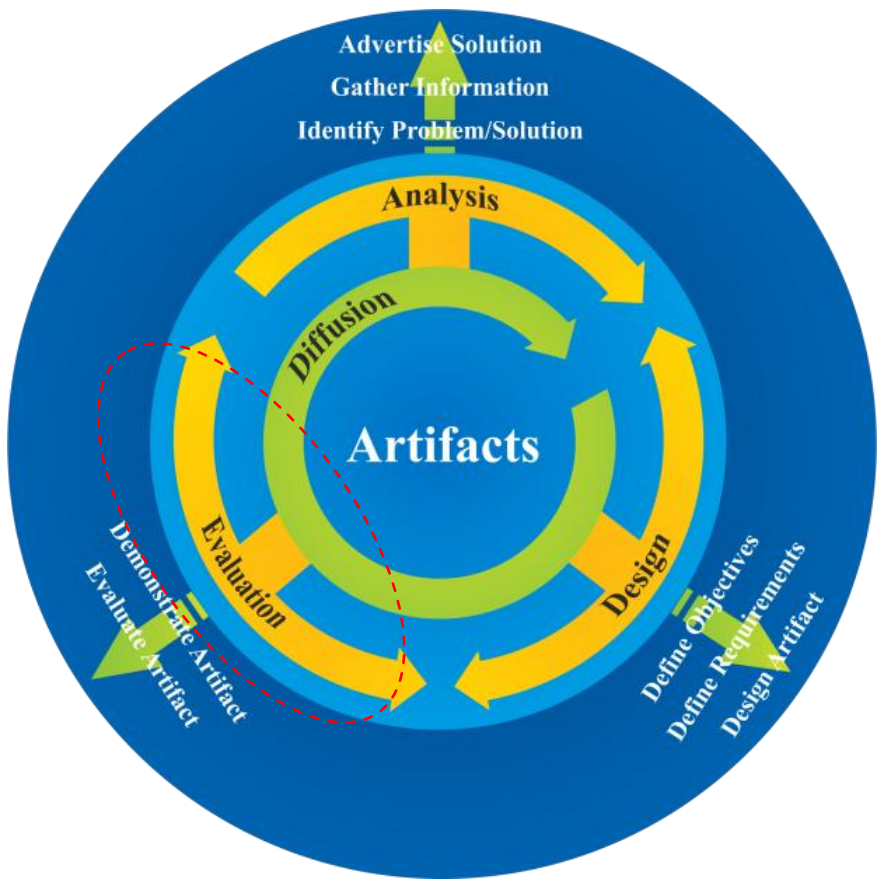

Fig. 1. DSR Artifact Build Cycle 
The evaluation of our research output in form of the EABW assessment is important; however despite many suggestions still challenging [28, 29]. It is necessary to justify the design and ensure that the intended approach satisfies the stakeholders. In its simplest form, evaluating a novel IT artifact means working or producing adequate results that help solving a problem [30]. Our research is conducted in collaboration with an industry partner and thus allows us to evaluate our IT artifacts in an organizational environment. This presents us with some interesting challenges, in regards to practice oriented and theoretical evaluations.

In literature, we can observe several different approaches for evaluations in a DSR context that are commonly differentiated into ex ante and ex post evaluations [32]. Thereby, ex ante evaluation is conducted before the decision to acquire or implement a new technology. Such decisions are further classified in [31]. A classification of various evaluation methods based on a limited literature review is presented in [29]. By far the most prominent method is the technical experiment to evaluate the technical performance rather than real world performance. The reason for this lies in the specific selection of literature which delivers algorithms as most frequently built artifact type. The importance of utility and quality for artifact evaluation is highlighted in [33].

Nevertheless, aggregated or combined evaluation techniques, i.e. the evaluation of connected artifacts, are still challenging. These are not necessarily in a hierarchy as described in [34]. As presented below, we therefore employ a method which also considers the actual organizational context in which we undertake our evaluation and the relationship between evaluated artifacts (cf. sec. 5).

\section{Artifact Design: Assessing Enterprise Architecture Business Value}

The benefits associated with EA are manifold. Several approaches for assessing EA have been developed, e.g. the DeLone and McLean model is adapted in [17]. In [18] a Balanced Scorecard approach for EA measurement is employed. How certain EA practices and techniques influence EA benefits is discussed by [4]. The concept of maturity models is also applied to the domain of EA and there exist several frameworks and approaches for these kinds of assessments [19]. A general view on EA maturity is given in [20] and the link of EABV and EA maturity is described in [21]. Critical problems in EA are described in [3] although the sections about assessments and metrics are very limited. EA measurement drivers and enablers are discussed in [22] without going into detail about challenges and problems. EA management challenges in terms of agile solutions is examined in [23]. As business IT alignment (BITA) is a major EA driver, the assessment of it is discussed by various contributions [24-27]. In the following we briefly introduce our Design Artifact: the Enterprise Architecture Business Value Assessment framework. 


\subsection{EABV Assessment Types}

EABV assessment is a continuous assessment because we employ a measurement process embedded into the daily EA operations, i.e. we constantly measure the EA operative performance. In contrast, a periodic assessment is an EA maturity assessment which captures the maturity of the overall EA capability. The EA capability determines how the EA function is executed and therefore has direct impact on the EA performance in operations. Nevertheless, statements about the business value of the EA function are tied to the operative performance since just attaching a maturity level to an EA capability tells us nothing about its actual impact in terms of EABV. We need to put the EA capability into practice. What we can do is to elaborate how EA performance is impacted by which EA capability.

Every EA assessment needs an input which is derived from the strategy. Strategy defines how the EA capability is set up and how it is executed. We need to derive goals for that purpose because we need to measure them whether successful or not. More on EA assessments including challenges and problems can be found in [11].

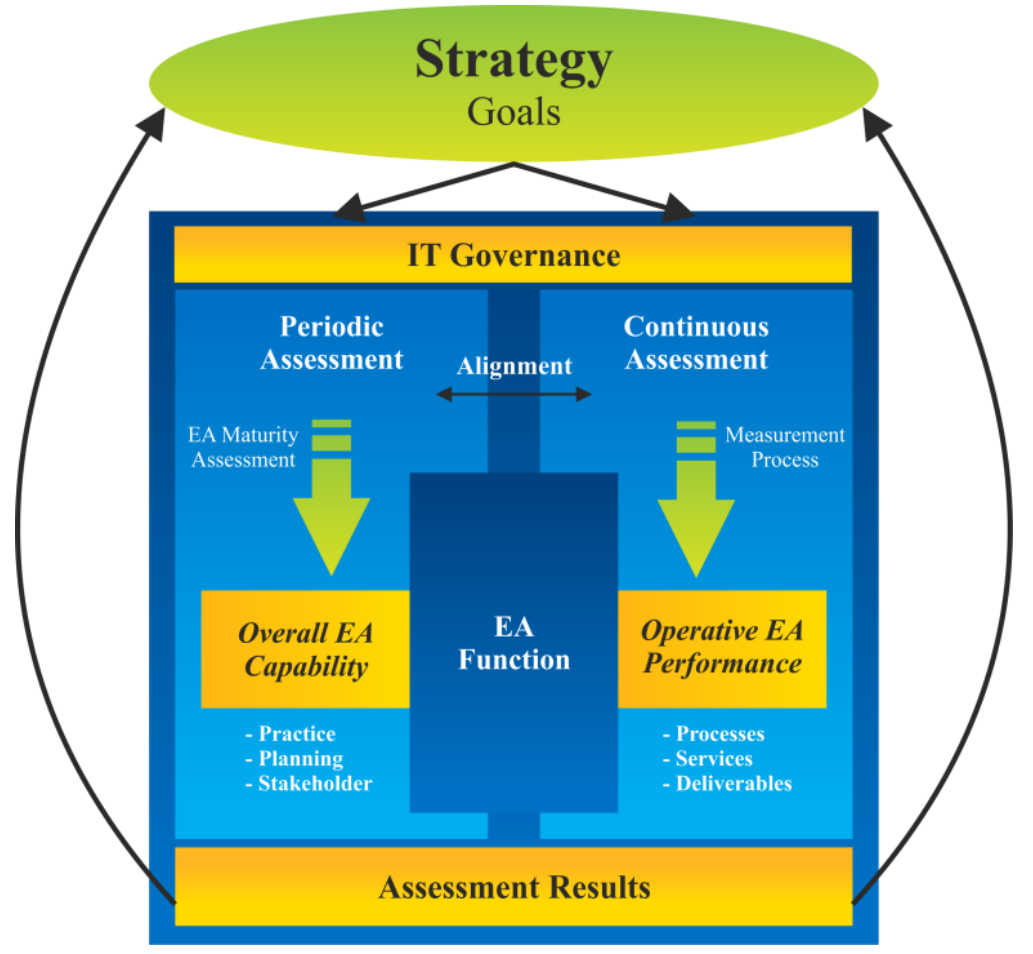

Fig. 2. EA Assessment Types 


\subsection{Stakeholder Perspectives relevant to Enterprise Architecture}

Each stakeholder or stakeholder group respectively possesses a different view on each IT artifact, i.e. he or she would have different preferences, opinions, and uses for a particular artifact [28]. Generally spoken, each stakeholder has different expectations of the benefits he or she will receive. Meeting stakeholder expectations poses a great challenge because goals and motivations are not always transparent and once known we must satisfy the stakeholder needs. For this purpose, we identified several stakeholder groups which are immediately affected by EA and are part of the EA assessment. These groups are based on previous periodic assessments conducted by our corporate partner. EA Managers are concerned about the strategy and high-level impact of EA. They are responsible for justifying the investments made and the overall quality of the EA outcome. EA Practitioners are Enterprise Architects at various levels of experience and are concerned about delivering quality output that is used by the EA Customers for their projects and programs. The stakeholder groups and their expected benefits are outlined in Table 1 .

Table 1. Expected Stakeholder Benefits from EA

\begin{tabular}{cll}
\hline Stakeholder Group & \multicolumn{2}{l}{ Expected Benefits } \\
\hline \multirow{2}{*}{ EA Managers } & $\bullet$ & Positive ROI \\
& - & Improved quality of EA function and corresponding output \\
& - & Improved strategic decisions \\
\hline \multirow{2}{*}{ EA Practitioners } & $\bullet$ & Reduced complexity in creating EA deliverables \\
& - & Improved processes for service delivery \\
\hline \multirow{2}{*}{ EA Customers } & $\bullet$ & Faster Time-to-Market for their services and products where EA \\
& & services are consumed \\
& - & Reduced complexity for their services and products \\
\hline
\end{tabular}

This list of perceived and reported benefits from EA is certainly not exhaustive but should demonstrate what stakeholders want to get out of the EA function and is based on the results of our survey as well as the literature review. A list with the most often perceived EA benefits can be found in [1], another list of EA benefits is composed in [4]. An example how different stakeholder groups perceive different EA benefits is illustrated in Fig. 3. As we can see, expected benefits overlap from for the chosen stakeholder groups. The perspectives determine the relevant goals stakeholders have regarding the EA function. As one of the main drivers for EA, the Business-IT Alignment (BITA) has been a major concern in recent literature $[35,36]$ and is a shared goal for all of our stakeholder groups. A more detailed take on stakeholder perception of EA is given in [37]. 


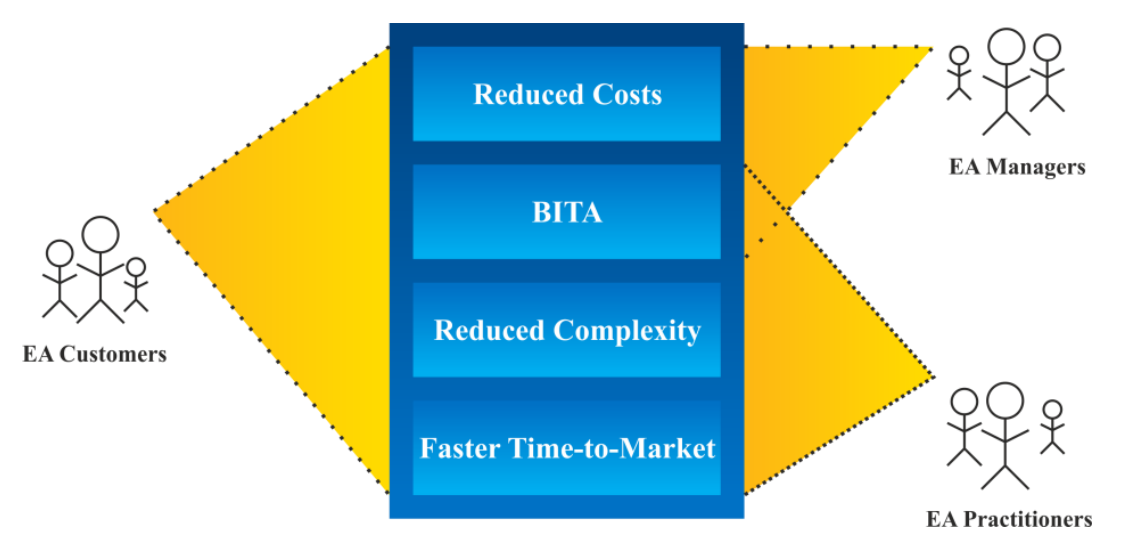

Fig. 3. Perspectives on EA benefits by stakeholder group

\subsection{EABV Assessment Approach}

Our EABV assessment approach consists of four IT artifacts; all designed using our Artifact Build Cycle. The main artifact is the EABV Framework. In order to provide a common understanding and a clear definition of what EABV is and how it is embedded into the organization, we built the EABV Model. Furthermore, we have the EABV Measurement Process which gathers relevant data about EABV and also provides means of reporting it in conjunction with the last artifact, an EABV Balanced Scorecard.

\section{Artifact Evaluation}

Evaluation of design-based artifacts has two major challenges. Firstly, a single individual cannot define all the criteria and constraints. Secondly, we must evaluate from different, sometimes conflicting, perspectives [38]. Before evaluating our approach, we need to choose the appropriate criteria, e.g. functionality, completeness, consistency, accuracy, performance, reliability, usability, fit with organization, and others more [12]. Generally, these criteria are derived from the artifact objectives [13]. We choose our criteria based on the artifact objectives and requirements. The evaluation context of the IT artifacts is an organizational one. Different output have different criteria for different perspectives, e.g. we can view our artifacts as either products or processes [32]. This leads to different perception of our chosen stakeholder group and therefore different evaluation criteria apply. We will discuss a criterion-based evaluation in this section, in which we discuss our selected evaluation method and describe how we applied it to our EABV assessment approach. 


\subsection{Measurement and Analysis Infrastructure Diagnostic}

The Measurement and Analysis Infrastructure Diagnostic (MAID) method [39] was designed to gain insights about how good a measurement and analysis system works in terms of certain criteria. In other words, an organization's data quality and means of information gathering and reporting can be assessed using this method. Consequently, it is the evaluation method of choice for our purposes. This method offers four phases, namely Collaborative Planning, Artifact Evaluation, On-Site Evaluation and Report Results. It has to be noted that the artifact in stage three is not an IT artifact in a DSR sense.

As a result, the method produces a detailed report about an organization's capability in measurement and analysis. This is the first of the two main MAID objectives with the other making recommendations for improvement. MAID is a collaborative effort and assigns clear roles and responsibilities for the evaluation team and other stakeholders from the assessed organization.

\subsection{MAID Application for Design Artifact Evaluation}

Having outlined the basic intent of MAID it is time to put it to action, i.e. we evaluate our EABV assessment approach. As we already mentioned in section 3, we have four different IT artifacts to assess EABV. We also outlined that there is little information about an aggregated evaluation in the DSR literature. When applying this method, we aim to assess the entire approach based on chosen criteria and map them to the individual artifacts accordingly. MAID offers approximately 325 different criteria. Nevertheless, if an individual artifact needs to be evaluated even more detailed, we can choose additional criteria. The extent of such detailed evaluation has to be in accordance with the organization's time and budget constraints and hence the choice of adequate criteria is a crucial task. We now take a closer look at the four main phases of MAID.

Collaborative Planning. In this phase, we first need to establish the scope of our evaluation. We want to identify the relevant business needs and objectives as well as what exactly is to be evaluated. In our case, we want to evaluate our IT artifacts. Furthermore, we need to determine the participating stakeholders that contribute to the evaluation as well as their tasks. Another crucial part is the evaluation plan and schedule where we define inputs and outputs and tailor the MAID method to our needs and requirements. Hereby, we also look at budget and time constraints.

Artifact Evaluation. Artifacts in this phase are all relevant measurement and analysis documents, tools, and data repositories. Consequently, DSR artifacts are considered as MAID artifacts and serve as input for the method since we want to evaluate them. We gather the relevant artifacts from the organizational context since our designed artifacts and their according output is already instantiated. We organize these artifacts and assign team members to evaluate them. The actual evaluation follows a criterion-based rating scale. The results are then reviewed for quality purposes. Finally, we need to prepare for the next phase, the On-Site Evaluation where we diffuse information material to support expert interviews and workshops following a detailed agenda. 
On-Site Evaluation. This phase includes many meetings and interviews in order to examine relevant data repositories. Hereby, we kick off with an orientation meeting to ensure all stakeholders or MAID team member respectively are on the same page and share a common understanding on how the evaluation will be conducted. During further meetings, the chosen criteria are rated as an outcome of the evaluation.

Report Results. The final phase of our evaluation starts off with the analysis of the On-Site Evaluation results. From these, we derive key findings and report them accordingly. The reports are structured and organized according to stakeholder and organizational needs. Based on these findings, we are able to plan the next steps. In other words, we determine where we want to go next within our artifact build cycle. For example, we could find out that our artifact design was not adequate to capture all the desired information which means that we need to step back to the Design phase (cf. Fig. 1) before we can conduct another evaluation.

\subsection{Application of Sample Criteria}

The number of different criteria is enormous so we just give a sample mapping of how one of our artifacts is evaluated using a selection of relevant criteria. The artifact evaluated is the EABV Measurement process which defines what and how we will extract information for the EABV assessment. A phase of this process is the actual measurement planning. Hence, we focus on the measurement and analysis ( $M \& A$ ) planning category on organizational level [40]. The selected criteria are illustrated in Table 2. Other categories for criteria are e.g. project specific ones.

Table 2. Mapping of relevant criteria to the planning phase of the EABV Measurement Process

\begin{tabular}{|c|c|}
\hline $\begin{array}{c}\text { Category } \\
\text { Level/Number }\end{array}$ & Description \\
\hline \multicolumn{2}{|l|}{ M \& A Planning } \\
\hline \multicolumn{2}{|l|}{$\begin{array}{l}\text { Organizational } \\
\text { Level }\end{array}$} \\
\hline 1.2 & Organizational business goals are defined and documented. \\
\hline 1.3 & Stakeholders of the business goals are explicitly defined. \\
\hline 1.4 & $\begin{array}{l}\text { Organizational business goals are expressed in measurable terms so } \\
\text { progress toward achieving a goal can be assessed. }\end{array}$ \\
\hline 1.6 & A measurement plan is documented. \\
\hline 1.8 & The plan specifies the resources that are to be allocated for ... \\
\hline 1.8.1 & ... staffing M \& A personnel. \\
\hline 1.8.3 & ... data storage \\
\hline 1.8.4 & ... reporting (communicating) \\
\hline 1.9 & Measurable business goals are documented in the plan. \\
\hline 1.10 & $\begin{array}{l}\text { A structured approach is followed to develop performance measures and } \\
\text { measurement indicators. }\end{array}$ \\
\hline
\end{tabular}




\section{Summary and Concluding Remarks}

In this paper, we presented an approach to evaluate an EABV assessment effort in a DSR context. The evaluation happens within the Evaluation phase of our Artifact Build Cycle. For this purpose, adapted a method to measure and analyze our four IT artifacts, namely the EABV Framework, the EABV Model, the EABV Measurement Process and the EABV Balanced Scorecard. Since we have not only one artifact, we are able to conduct an aggregated criterion-based evaluation with MAID. The level of detail for each of the artifacts is determined by the stakeholders and can be adapted according to organizational needs such as time and budget. We presented a mapping of sample criteria for one of the artifacts to illustrate the basis of our aggregated evaluation while still allowing for a detailed individual evaluation. Our evaluation effort is within an organizational context which allows us to incorporate valuable practitioner contribution along the insights gained from academic literature.

With this contribution, we proposed an example on how to evaluate an EABV assessment approach in an organizational and DSR context. We conducted a pilot assessment and researchers as well as practitioners found it to be reasonable and feasible.

\section{Acknowledgments}

This work is partly funded by the Irish Research Council (IRC).

\section{References}

1. Ross, J.W., P. Weill, and D.C. Robertson, Enterprise Architecture as Strategy, Boston: Havard Business Press (2006)

2. Ahlemann, F., C. Legner, and D. Schäfczuk, Introduction, in Strategic Enterprise Architecture Management - Challenges, Best Practices, and Future Developments, F. Ahlemann, et al., Editors, Springer: Berlin Heidelberg. p. 1-34 (2012) http://dx.doi.org/10.1007/978-3-642-24223-6_1 http://dx.doi.org/10.1007/978-3-642-24223-6

3. Kaisler, S.H., F. Armour, and M. Valivullah. Enterprise Architecting: Critical Problems. Proceedings of the 38th International Conference on System Sciences, Hawaii: IEEE (2005)

4. van Steenbergen, M., et al. Achieving Enterprise Architecture Benefits: What Makes the Difference? 15th International Enterprise Distributed Object Computing Conference Workshops, Helsinki, Finland (2011) http://dx.doi.org/10.1109/EDOCW.2011.36

5. Ross, J.W. and P. Weill Understanding the Benefits of Enterprise Architecture. CISR Research Briefing (2005)

6. Shang, S. and P.B. Seddon, Assessing and Managing the Benefits of Enterprise Systems: The Business Manager's Perspective, in Information Systems Journal, p. 271-299 (2002) http://dx.doi.org/10.1046/j.1365-2575.2002.00132.x 
7. Fotini, M., S. Anthi-Maria, and L. Euripidis, ERP Systems Business Value: A Critical Review of Empirical Literature, in Panhellenic Conference on Informatics, IEEE (2008)

8. Mitra, S., V. Sambamurthy, and G. Westerman, Measuring IT Performance and Communicating Value, in MISQ Executive, p. 47-59 (2011)

9. Brynjolfsson, E., L.M. Hitt, and S. Yang, Intangible Assets: Computers and Organizational Capital, in Brookings Papers on Economic Activity, p. 137-181 (2002) http://dx.doi.org/10.1353/eca.2002.0003

10.Vasconcelos, A., P. Sousa, and J. Tribolet, Information System Architecture Metrics: An Enterprise Engineering Evaluation Approach, in Electronic Journal of Information Systems Evaluation, p. 91-122 (2007)

11.Meyer, M. and M. Helfert. Challenges and Problems of Enterprise Architecture Assessments - Lessons Learned. in Proceedings of the 7th Mediterranean Conference on Information Systems (2012)

12.Hevner, A.R., S.T. March, and J. Park, Design Science in Information Systems Research, in MIS Quaterly, p. 75-105 (2004)

13.Österle, H., et al., Memorandum on Design-oriented Information Systems Research, in European Journal of Information Systems, p. 7-10 (2011)

14.Peffers, K., et al., A Design Science Research Methodology for Information Systems Research, in Journal of Management Information Systems, p. 45-77 (2008)

15.Meyer, M., et al. Applying Design Science Research for Enterprise Architecture Business Value Assessments. in DESRIST, Springer (2012)

16. Meyer, M. and J. Kenneally, Applying Design Science Research in Enterprise Architecture Business Value Assessments, in Practical Aspects of Design Science, M. Helfert and B. Donnellan, Editors, Springer, p. 151-157 (2012) http://dx.doi.org/10.1007/978-3-642-33681-2_13

17.Niemi, E. and S. Pekkola. Adapting the Delone and McLean Model for the Enterprise Architecture Benefit Realization Process. in Proceedings of the 42nd Hawaii International Conference on System Sciences, IEEE (2009)

18.Schelp, J. and M. Stutz, A Balanced Scorecard Approach to Measure the Value of Enterprise Architecture, in Journal of Enterprise Architecture (2007)

19.Meyer, M., M. Helfert, and C. O'Brien. An Analysis of Enterprise Architecture Maturity Frameworks. in BIR 2011, LNBIP 90, Springer (2011)

20.Ross, J.W., Creating a Strategic IT Architecture Competency: Learning in Stages. MISQ Executive, 2(1): p. 31-43 (2003)

21.Bradley, R.V., et al., The Role of Enterprise Architecture in the Quest for IT Value. MIS Quarterly Executive, 10(2) (2011)

22.Murer, S., B. Bonati, and F.J. Furrer, Managed Evolution - A Strategy for Very Large Information Systems2011, Berlin Heidelberg: Springer.

23.Buckl, S., et al. Towards an Agile Design of the Enterprise Architecture Management Function. in 15th IEEE International Enterprise Distributed Object Computing Conference Workshops, IEEE (2011)

24.Masak, D., IT-Alignment: IT-Architektur und Organisation, Springer (2006)

25.Luftman, J.N., Assessing Business-IT Alignment Maturity, in Communications of the Association for Information Systems (2000) 
26.Zimmermann, S., Governance im IT-Portfoliomanagement - Ein Ansatz zur Berücksichtigung von Strategic Alignment bei der Bewertung von IT, in Wirtschaftsinformatik, p. 357-365 (2008)

27.van der Raadt, B., J.F. Hoorn, and H. van Vliet, Alignment and Maturity Are Siblings in Architecture Assessment, in LNCS Advanced Information Systems Engineering, O. Pastor and J. Falcao e Cunha, Editors, Springer, p. 71-92 (2005) http://dx.doi.org/10.1007/11431855_25

28.Hevner, A. and S. Chatterjee, Design Research in Information Systems - Theory and Practice: Springer (2010) http://dx.doi.org/10.1007/978-1-4419-5653-8

29.Peffers, K., et al., Design Science Research Evaluation, in LNCS 7286, K. Peffers, M.A. Rothenberger, and B. Kuechler, Editors. 2012, Springer: DESRIST, p. 398410 (2012)

30.Niederman, F. and S.T. March, Design Science and the Accumulation of Knowledge in the Information Systems Discipline. ACM Transactions on Management Information Systems (TMIS), 3(1) (2012)

31.Bannister, F. and D. Remenyi, Acts of Faith: Instinct, Value and IT Investment Decisions. Journal of Information Technology, 15(3), p. 231-241 (2000) http://dx.doi.org/10.1080/02683960050153183

32.Pries-Heje, J., R. Baskerville, and J. Venable. Strategies for Design Science Research Evaluation. in ECIS (2008)

33.Helfert, M., B. Donnellan, and L. Ostrowski, The Case for Design Science Utility and Quality - Evaluation of Design Science Artifact within the Sustainable ICT Capability Maturity Framework. Systems, Signs \& Actions, 6(1), p. 46-66 (2012)

34.Simon, H.A., The Sciences of the Artificial: MIT Press (1996)

35.Magoulas, T., et al., Alignment in Enterprise Architecture: A Comparative Analysis of Four Architectural Approaches. Electronic Journal of Information System Evaluation, 15(1): p. 53-62 (2012)

36.Schöenherr, M., Towards a Common Terminology in the Discipline of Enterprise Architecture, in LNCS 5472, G. Feuerlicht and W. Lamersdorf, Editors, Springer: Berlin Heidelberg. p. 400-413 (2008)

37.van der Raadt, B., S. Schouten, and H. van Vliet, Stakeholder Perception of Enterprise Architecture, in LNCS 5292, R. Morrison, D. Balasubramaniam, and K. Falkner, Editors, Springer. p. 19-34 (2008)

38.Bonnardel, N. and T. Sumner, Supporting Evaluation in Design. Acta Psychologica,. 91: p. 221-244 (1996) http://dx.doi.org/10.1016/0001-6918(95)00057-7

39.Kasunic, M., Measurement and Analysis Infrastructure Diagnostic 1.0: Method Definition Document, Software Engineering Institute (2010)

40.Kasunic, M., Measurement and Analysis Infrastructure Diagnostic (MAID) Evaluation Criteria 1.0, Software Engineering Institute (2010) 